\title{
Estudio de la carga energética celular en el trasplante renal experimental con diferentes periodos de isquemia caliente (0-30-45 y 90')
}

\author{
Álvarez-Vijande R, Luque Gálvez P, Alcaraz Asensio A y Grupo de Trasplante Renal Experimental* \\ Hospital Clinic Barcelona. Laboratorio Cirugía Experimental. Facultad de Medicina \\ Universidad de Barcelona. \\ Actas Urol Esp. 2008;32(1):41-58
}

\begin{abstract}
RESUMEN
ESTUDIO DE LA CARGA ENERGETICA CELULAR EN EL TRASPLANTE RENAL EXPERIMENTAL CON DIFERENTES PERIODOS DE ISQUEMIA CALIENTE (0-30-45 y 90')

Introducción: La posibilidad de obtener órganos para Trasplante Renal, tras un período de parada cardio-circulatoria, exige un conocimiento previo del mecanismo de lesión por isquemia-reperfusión.

Para poder estudiar el mecanismo de lesión celular por isquemia caliente en Trasplante Renal se ha diseñado un estudio experimental en cerdos, con tiempos variables (0-30-45 y 90' de isquemia caliente) con la finalidad de conocer el mecanismo celular de dicha lesión isquémica.

La determinación de parámetros bioquímicos (creatinina y diuresis), carga energética (ATP, ADP, AMP y carga energética global) y estudio histológico, así como análisis de supervivencia del animal e injerto al $5^{\circ}$ día.

Resultados:

- La supervivencia de los animales a los 5 dias ha sido del 100\% (en los grupos control y 30' de isquemia caliente), $90 \%$ (en los $45^{\prime}$ ) y $60 \%$ (en los 90 ').

- La viabilidad del injerto ha sido 100\% (grupo control), 80\% (isquemia 30'), 80\% (isquemia 45') y 60\% (90').

- Los niveles de creatinina aumentan al $1 \mathrm{er}$, 3er y $5^{\circ}$ día sobre todo en los riñones no viables con diferencias estadísticamente significativas con respecto al grupo control.

- Los niveles de ATP decrecen tras el período de isquemia caliente, aumentan los niveles de ADP y AMP y se recuperan en los riñones viables después de la reperfusión del injerto.

Conclusiones: El tiempo de isquemia caliente influye en la supervivencia del animal y del injerto, pero órganos con elevados períodos de isquemia caliente $\left(90^{\prime}\right)$ pueden ser viables. La carga energética celular se deteriorará con los períodos de isquemia caliente y fría, recuperando los niveles de nucleótidos y carga energética global los riñones viables. Los riñones con períodos de isquemia caliente breve recuperan antes los niveles de carga energética.

$\mathrm{El}$ estudio de niveles de carga energética celular ha demostrado ser un buen método para conocer el mecanismo de lesión celular isquémica (dentro del mecanismo de lesión de isquemia-reperfusión) en Trasplante Renal Experimental.

Palabras clave: Isquemia caliente. Reserva energética. Donante a corazón parado.
\end{abstract}

\section{ABSTRACT}

CELL ENERGETIC LOADING IN EXPERIMENTAL RENAL TRANSPLANT UIT DIFFERENT PERIODS OF WARM ISCHEMIA

Introduction and goals: Renal procurement after a period of heart stop demands a previous knowledge of ischemia-reperfusion injuries means. To study cell injury mechanisms an experimental study has been designed in pigs, with different rangres of warm ischemia (0-30-45 and $90 \mathrm{~min})$. The main goal was to research on the basis of ischemic injury.

Material and methods: Biochemical parameters (creatinine, urine output), energetic loading (ATP, ADP, AMP and global energetic loading) and pathological studies as long as survival analysis by 5 th day were completed.

Results: Animal survival and graft viability range from $100 \%$ at 5 th day in control and 30 min warm ischemia groups to $60 \%$ in $90 \mathrm{~min}$ warm ischemia group. Creatinine levels rises at 1st, 3rd and 5th day, especially in those non-viable organs. ATP levels decrease after warm ischemia period, increases ADP and AMP levels after reperfusion in those viable organs.

Conclusions. Prolonged periods of warm ischemia do not result necessarily in non-viable kidneys. Viable organs recover nucleotide levels early.

Study of energetic cell loading levels is a good way to get on better in the knowledge of injury mechanisms after ischemiareperfusion.

Keywords: Warm ischemia. Energetic resource. Non heart beating organ donor.

*Integrantes Grupo Trasplante Renal Experimental: Alcoberro J, Gibanel R, Calatrava P, Aguilar A, Méndez D, Capdevila S, Peri Ll, Rodriguez A, Arch A, Agud A, Solé M, Helena, Jiménez W. 
$\mathrm{E}^{1}$ interés de obtener órganos a partir de donantes a corazón parado no es nuevo. En la década de 1960 a 1970, antes de que el concepto de muerte cerebral fuera establecido, la principal fuente de obtención de órganos eran los individuos en los que ya había ocurrido la parada cardíaca.

E1 número de donantes potenciales por millón de habitantes se encuentra alrededor de 30. A pesar de que España tiene el índice de donación de órganos por millón de habitantes más alto del mundo (32 según ONT, actividad de donación y trasplante en 1999), y el número de donantes cada vez es mayor, continúa habiendo un déficit de órganos, conllevando una mortalidad en la lista de espera de hasta un $6,8 \%$ en 1994.

La falta persistente de órganos aptos para trasplante obliga a la utilización de todos los medios humanos y técnicos en la investigación de soluciones alternativas.

\section{FUENTES DE OBTENCIÓN DE ÓRGANOS ALTERNATIVAS \\ Donante marginal}

Como consecuencia de esta escasez, se han ido ampliando cada vez más los criterios de selección de los cadáveres donantes de órganos ${ }^{1,2}$ para con ello, aumentar al máximo el número de órganos disponibles.

Los donantes marginales, pues tienen, previo a la extracción, una estancia prolongada en UCI, con drogas vasoactivas, patologias asociadas a la edad como hipertensión arterial, diabetes mellitus, etc. Se están utilizando de forma creciente, llegando a convertirse en donantes más habituales.

\section{Donante a corazón parado}

La discrepancia actual que existe entre la oferta y la demanda de órganos ha obligado recientemente a explorar otras fuentes de donantes que permitan aumentar el número, reavivando el interés por los donantes a corazón parado. El programa de obtención de riñones de donantes a corazón parado se inició en 1980 en el Hospital Universitario de Maastrich ${ }^{3}$. Se calcula que el número de donantes potenciales podría aumentar así en un $20 \%{ }^{4}$.
Se define donante a corazón parado como aquel individuo en situación de parada cardiorrespiratoria irrecuperable, fallecido con un tiempo de isquemia caliente (tiempo entre la parada cardíaca y el inicio de la perfusión fría) lo suficientemente corto que permita la extracción de órganos viables para ser utilizados para trasplante.

En Marzo de 1995, en el First International Workshop on Non Heart-Beating Donors, celebrado en Maastricht se realizó un documento de consenso ${ }^{5}$ estableciéndose una serie de recomendaciones, definiciones y características de lo que debian ser los donantes a corazón parado. Se propuso una clasificación en 4 categorias (Clasificación de Maastricht) ${ }^{6}$.

En España este documento se ha adaptado a nuestro ambiente, quedando las conclusiones plasmadas en un Documento de Consenso Español emitido por la Organización Nacional de Trasplantes en Noviembre de 19957

- Categoría I: Ingreso en parada cardíaca.

- Categoría II: Parada cardiaca con maniobras de reanimación inefectivas

- Categoría III: A la espera de la parada cardíaca.

- Categoría IV: Donante en muerte cerebral que sufre una parada cardíaca.

La inclusión de donantes a corazón parado en el grupo de donantes aptos para trasplante ha supuesto un incremento en el número total de donantes entre un $7 \%$ y un $20 \%$ según las series ${ }^{4}$.

El trasplante renal acumula la mayor parte de órganos con donantes a corazón parado. Aunque en estos momentos sea relativamente corta la casuística ha dado lugar a un gran número de publicaciones. Todas ellas coinciden en que los riñones así obtenidos son útiles para trasplante ${ }^{8-26}$. A pesar de tener una mayor incidencia de fracaso de la función inicial, su supervivencia a largo plazo se aproxima a la obtenida con aquellos riñones provenientes de donantes con corazón latiendo ${ }^{27-29}$.

Es importante conocer en profundidad lo que ocurre en un riñón después de un período de isquemia caliente (durante la parada cardiaca) y su posterior reperfusión con el objetivo de poder actuar sobre el potencial injerto.

\section{Lesión por isquemia reperfusión}

La lesión de isquemia-reperfusión se define como el proceso que sufre un órgano sometido 
temporalmente a la falta de flujo sanguíneo y que posteriormente es reperfundido con sangre oxigenada. El resultado es una agresión tisular secundaria a la anoxia, a la deprivación de metabolitos y al acúmulo de sustancias de deshecho del metabolismo que conduce a la muerte de la célula.

Durante el trasplante de un órgano este fenómeno ocurre, pudiendo ser la lesión de intensidad variable. Bien se puede alterar la función del órgano de forma discreta conllevando a una disfunción inicial del injerto; bien puede convertirse en lesión irreversible imposibilitando la viabilidad del órgano.

En los donantes a corazón parado, la lesión por isquemia es más importante, dado que se añade un tiempo de isquemia caliente, más o menos prolongada, a la habitual isquemia fría, de manera que existe un mayor riesgo para su viabilidad a corto y largo plazo.

El empeoramiento de la función del órgano derivado del daño producido por el síndrome de isquemia-reperfusión es todavía un problema importante en el trasplante de órganos sólidos. Las alteraciones celulares, inducidas por la isquemia, preparan al tejido para el siguiente daño que ocurre durante la fase de reperfusión. Paradójicamente, el reestablecimiento del flujo sanguíneo al tejido isquémico puede causar mayor daño que el inducido durante el período de isquemia.

El síndrome de isquemia-reperfusión es una secuencia compleja de sucesos trascendentales: la alteración metabólica a nivel celular que aparece durante el período de isquemia y la lesión producida por los radicales libres derivados del oxígeno y otros factores que involucran al endotelio vascular y los polimorfonucleares durante la reperfusión ${ }^{30}$.

Se produce una alteración de la membrana plasmática, inhibiéndose la actividad de la ATPasa Na-K, que es la bomba sodio-potasio transmembrana (transporta $\mathrm{Na}$ hacia el exterior celular y $\mathrm{K}$ hacia el interior), produciéndose una alteración del intercambio de los iones sodio, potasio y calcio, por lo que el potencial de membrana queda abolido. Debido a la elevada concentración de cloro fuera de la célula y a la presencia de proteínas dentro de la misma (efecto Donnan: se crea una presión oncótica coloidal intracelular alta) el cloro penetra dentro de la célula con un catión (sodio y calcio) arrastrando agua y el potasio sale fuera para mantener el equilibrio iónico con el espacio intersticial. Todo ello conduce al edema celular y activación de enzimas por el calcio como fosfolipasas (que provocarán lesión de las diferentes membranas: citoplasmática, mitocondrial, lisosomal), proteasas, ATPasas (deplección de ATP) y endonucleasas (fragmentación de cromatina) conllevando a la muerte por citolisis.

Por otra parte, la falta de oxígeno durante el período de isquemia impiden, a nivel de la mitocondria la fosforilación oxidativa, con escasa formación de ATP, quedando paralizadas todas las funciones celulares que requieran energía y se estimula la glicolisis anaerobia formándose ácido láctico e hidrogeniones dando lugar a la acidosis intracelular ${ }^{31-33}$. Ésta, provoca la activación de los enzimas de los lisosomas conduciendo a la autolisis y muerte celular.

Granger, Rutili y McCord ${ }^{34}$ fueron los primeros (1981) en proponer un mecanismo molecular para explicar la producción de lesiones en el síndrome de isquemia-reperfusión: durante el periodo de isquemia se produce consumo de ATP por parte de las células para mantener la homeostasis. El ATP es catabolizado a ADP y AMP (Fig.1). El AMP, a su vez, se cataboliza a hipoxantina, produciéndose un acúmulo de ésta. La carga energética de las células ha caído y éstas no son capaces de mantener el gradiente iónico entre sus membranas, redistribuyéndose el calcio hacia el interior de la célula y aumentando la concentración de calcio en el interior de ésta. Los acúmulos de xantinooxidasa y de sus sustratos: hipoxantina y xantina durante el periodo de isquemia, parecen ser los acontecimientos necesarios para producir la lesión en las células durante la posterior reoxigenación, puesto que llegará el $\mathrm{O}_{2}$ necesario para el enzima con la consecuente producción de radicales libres de oxígeno.

\section{Alteraciones celulares durante la reperfusión}

Durante el periodo de reperfusión:

La xantinooxidasa es la mayor fuente de superóxidos en tejidos postisquémicos ${ }^{31,35}$. Este enzima fue la primera fuente biológica documentada 


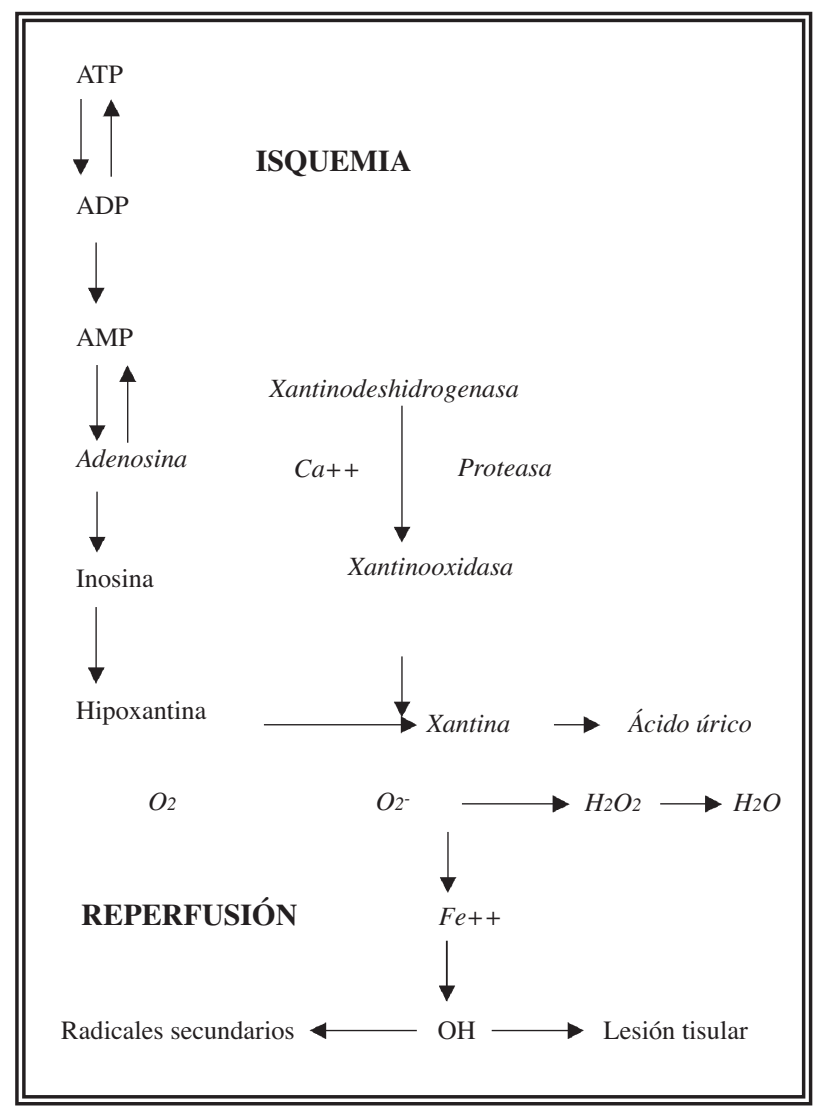

FIGURA 1. Mecanismo de producción del sindrome de isquemia-reperfusión.

Los nucleótidos de la adenina se hidrolizan progresivamente durante el periodo de isquemia, con la consecuente acumulación de hipoxantina. Durante la reperfusión, la entrada masiva de oxigeno originará los RLO que provocarán la lesión en los tejidos. Las oxipurinas son permeables a través de la membrana celular y pasan al espacio extracelular disminuyendo los precursores de la sintesis de ATP.

de producción del radical superóxido. Es sintetizada en forma de xantinodeshidrogenasa (forma habitual en tejidos normóxicos). La xantinodeshidrogenasa no puede transferir electrones al oxígeno molecular para formar peróxido de hidrógeno o superóxido, pero puede reducir el $\mathrm{NAD}^{+}$(nicotinamida adeninnucleótido) de la siguiente manera:

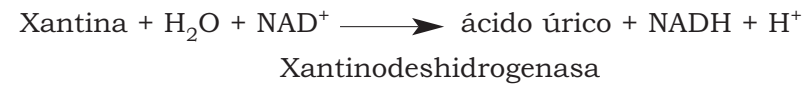

En condiciones de baja concentración de $\mathrm{O}_{2}$ como ocurre durante la isquemia, la xantinodeshidrogenasa se convierte en xantinoxidasa. Esta, puede usar el oxígeno molecular en lugar del NAD produciendo superóxido y peróxido de hidrógeno de la siguiente manera:
Xantinooxidasa

Xantina $+\mathrm{H}_{2} \mathrm{O}+2 \mathrm{O}_{2} \longrightarrow$ ácido úrico $+2 \mathrm{O}_{2}{ }^{-}+2 \mathrm{H}^{+}$

Así, la xantinooxidasa, aprovechando el acúmulo de xantina e hipoxantina originados durante la isquemia, junto con el oxígeno que le llega con la reperfusión, origina los denominados radicales libres de oxígeno (RLO) ${ }^{36}$.

Actualmente se piensa que los RLO causan dos tipos de lesiones:

a) Daño celular producido por la oxidación de los lípidos, proteínas, ácidos nucleicos y lipoperoxidación ${ }^{37-39}$.

b) Los RLO, producen una disfunción del endotelio vascular ${ }^{30,40-45}$ causando una disminución en la liberación de óxido nítrico.

\section{MATERIAL Y METODOS}

Todos los estudios se han realizado en el Laboratorio y Estabulario de Cirugía Experimental de la Facultad de Medicina de la Universidad de Barcelona y Hospital Clínico de Barcelona.

Para poder estudiar el mecanismo de lesión isquémica, con diferentes tiempos de isquemia caliente, se ha diseñado el siguiente método de estudio en animal de experimentación.

GRUPO 0 ( $n=5$ pares). CONTROL. Sin isquemia caliente.

GRUPO 1 ( $\mathrm{n}=10$ pares). Periodo de isquemia caliente de 30 minutos.

GRUPO 2 ( $\mathrm{n}=10$ pares). Período de isquemia caliente de 45 minutos.

GRUPO 3 ( $\mathrm{n}=10$ pares). Período de isquemia caliente de 90 minutos.

El estudio experimental realizado se basa en el siguiente diseño:

1. Premedicación y anestesia del animal donante.

2. Incisión de laparatomía media xifopubiana.

3. Disección de extremo caudal de arteria Aorta y vena Cava y canulación de ambas.

4. Heparinización del animal donante.

5. Provocación de la parada cardíaca: 30,45 ó 90 minutos.

6. Perfusión renal fría con solución de Wisconsin.

7. Extracción renal y cirugía de banco.

8. Preservación a $4{ }^{\circ} \mathrm{C}$ durante 6 horas.

9. Preparación del animal receptor. 
10. Nefrectomía bilateral en el receptor.

11. Implante del injerto renal. Fin del período de isquemia fría.

12. Control y seguimiento durante 5 días postoperatorios.

13. Sacrificio del animal al quinto día.

Modelo experimental: se ha optado por la provocación de la parada cardiaca mediante la inyección intravenosa de 20-30 mEq de ClK. Se trata de un método sencillo y rápidamente eficaz para lograr un período de isquemia caliente homogéneo y bien controlado, esto permite su reproducibilidad en todos los grupos del estudio.

Los pares de animales son divididos en 4 grupos. Se detallan a continuación las características de cada grupo:

GRUPO 0 ( $\mathrm{n}=5$ pares). CONTROL. Extracción a corazón latiente del riñón donante posterior a la perfusión renal con un litro de solución fría de UW y almacenaje en nevera a $4^{\circ} \mathrm{C}$ durante 6 horas, tras las cuales se realiza el trasplante.

GRUPO 1 ( $\mathrm{n}=10$ pares). Período de parada cardiaca de 30 minutos seguido de perfusión renal con un litro de solución fría de UW.

GRUPO 2 ( $\mathrm{n}=10$ pares). Período de parada cardíaca de 45 minutos seguido de perfusión renal con un litro de solución fría de UW.

GRUPO 3 ( $\mathrm{n}=10$ pares). Período de parada cardiada de 90 minutos seguido de perfusión renal con un litro de solución fría de UW.

\section{TECNICA QUIRÚRGICA EN EL DONANTE}

En la laparatomía xifopubiana se disecan la arteria Aorta y la vena Cava en su extremo más distal para la canulación y previa a la heparinización del animal a dosis de $3 \mathrm{mg} / \mathrm{kg}$ peso, se provoca entonces la parada cardiaca mediante la inyección intravenosa de 20-30 mEq de ClK. En el grupo control del estudio se extraen los riñones a corazón latiente, una vez perfundidos con UW, sin período de isquemia caliente.

Tras los minutos de isquemia caliente correspondientes a cada grupo (30, 45 y 90 minutos) se procede a la perfusión fría "in situ" de los riñones a través de la arteria aorta con un litro de Solución de Wisconsin. Previamente, se había ocluido la aorta por debajo del tronco celíaco y se había ligado la arteria mesentérica superior. Se liga la vena cava inferior por debajo de las venas renales.
Una vez se estima finalizado el período de perfusión fría, se procede a la extracción de los riñones.

\section{CIRUGÍA DE BANCO}

La arteria renal tendrá un patch de aorta y la vena renal de cava.

Los riñones ya preparados se colocan en una bolsa de órganos estéril con suero Ringer Lactato "pilé" a $4{ }^{\circ} \mathrm{C}$ y se introducen en una nevera portátil con abundante hielo que la rodeará. Permanecerán durante 6 horas hasta su colocación en el receptor.

\section{TÉCNICA QUIRÚRGICA EN EL RECEPTOR}

\section{Nefrectomia bilateral en el receptor}

Se practica inicialmente una pequeña incisión de lumbotomía izquierda extraperitoneal hasta llegar al riñón izquierdo, realizando nefrectomía. Seguidamente se practica una incisión pararrectal derecha extraperitoneal disecando el riñón derecho y el hilio y la pelvis renal, ligando el pedículo renal en bloque y seccionando la vía renal a nivel de pelvis preservando el uréter propio.

\section{Implante de un riñón}

Se coloca el riñón derecho donante a nivel del retroperitoneo del cerdo receptor. Se realiza disección de la vena cava inferior y de la aorta ligando los vasos linfáticos a nivel de la zona donde realizaremos la anastomosis: generalmente en el territorio comprendido entre bifurcación de los vasos renales y bifurcación de los vasos ilíacos.

Primero se realiza la anastomosis términolateral entre vena renal; en segundo lugar la anastomosis término-lateral entre arteria renal con patch de aorta y aorta. Ambas anastomosis se realizan con sutura continua $180^{\circ}$ con monofilamento irreabsorvible Prolene 6 ceros; la cara posterior por dentro y la anterior por fuera. La reconstrucción del tracto urinario se realiza con sutura continua mediante pieloureterostomía dejando tutorizada ésta con un pig-tail.

La analgesia se realiza con Meperidina intramuscular (50-100 mg) durante la fase del despertar.

El tratamiento inmunosupresor se inicia después de la inducción anestésica con una dosis de $250 \mathrm{mg}$ de metilprednisolona y $1,5 \mathrm{mg} / \mathrm{kg}$ de aza- 
tioprina. Antes de la reperfusión renal, se administran $250 \mathrm{mg}$ de metilprednisolona de nuevo. A partir de las 24 horas, se administra ciclosporina oral a dosis de $20 \mathrm{mg} / \mathrm{kg} /$ dia hasta el día del sacrificio.

El sacrificio del animal se realiza con Tiopental sódico y Cloruro potásico (20-30 mEq) por vía endovenosa el quinto día del trasplante.

\section{DETERMINACIONES ANALÍTICAS Y BIOPSIAS}

\section{Momentos de la recogida de muestras}

Las muestras de sangre y de tejido renal se obtienen en los siguientes momentos definidos.

1. En el animal donante una vez colocados los catéteres, antes de iniciar la parada cardíaca. Sirve como muestra basal (B) del propio animal (sangre, orina y biopsias).

2. Al final del período de parada cardíaca (PC). Traduce la lesión aparecida durante todo el periodo de isquemia caliente (sangre y biopsias).

3. Inmediatamente antes de la reperfusión vascular en el animal receptor, durante la realización del trasplante (PR). Traduce la lesión después del período total de isquemia (sangre y biopsias).

4. Una hora después de la reperfusión vascular (1R). Traduce la lesión por isquemiareperfusión (sangre y biopsia).

5. Al primer día (1D), sólo se obtiene una muestra de sangre (bioquímica) para control evolutivo.

6. Al tercer día (3D), también únicamente se obtiene una muestra de sangre con el mismo fin.

7. Al quinto día (5D), en el animal superviviente (sangre, orina y biopsias) (Figs. $2 \mathrm{y}$ 3).

\section{Marcadores de lesión celular renal}

Desde el punto de vista biológico, la lesión renal se manifiesta como un aumento de la creatinina sérica que se traduce clínicamente en una insuficiencia renal postoperatoria de diferente grado. Para cuantificar el nivel de creatinina a lo largo del estudio, se obtienen en cada momento $6 \mathrm{ml}$ de sangre que se depositan en un tubo al vacío (Vacutainer) y se deja a temperatura ambiente. Posteriormente se

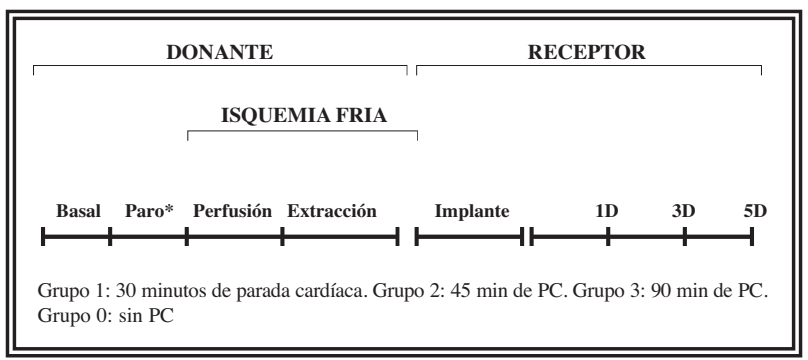

FIGURA 2. Esquema de las diferentes fases del estudio.

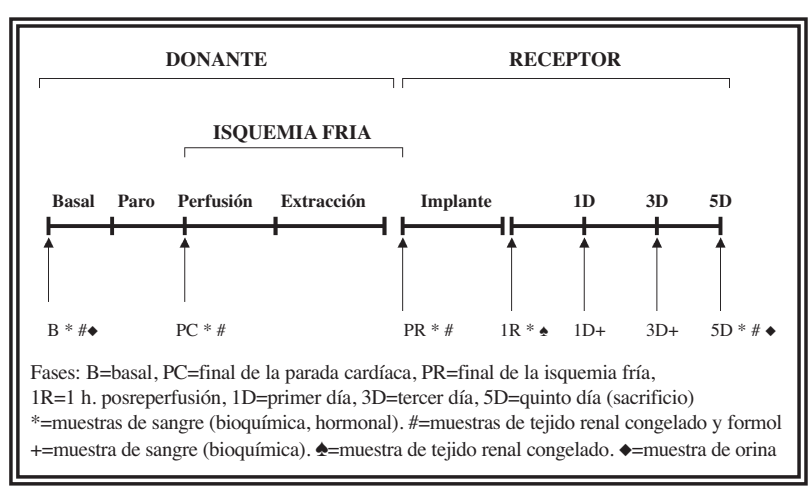

FIGURA 3. Esquema de las diferentes fases del estudio y momentos de toma de muestras.

centrifuga a 4000 rpm durante 10 minutos; el plasma se almacena en alicuotas de $1 \mathrm{ml}$ en microtubos Eppendorf y se congela a $-20^{\circ} \mathrm{C}$.

\section{Marcadores del estado energético celular}

La valoración de la reserva energética renal consiste en cuantificar la energía acumulada en la célula renal. Varios parámetros reflejan el estado energético del tejido: el nivel de ATP tisular, el nivel del total de nucleótidos de la adenina y la carga energética tisular (CE).

El nivel de ATP celular indica el nivel de energía que dispone el tejido. La carga energética representa la habilidad de los mecanismos tisulares para producir energía y esto se correlaciona con la función mitocondrial. Es decir, indica el potencial intacto del tejido para producir energia en detrimento de la cantidad del sustrato que dispone/ATP o precursores.

En los momentos del estudio se obtiene una biopsia renal que se congelará rápidamente a $-170^{\circ} \mathrm{C}$ en nitrógeno líquido con el fin de detener el rápido proceso de degradación del ATP. Seguidamente, se guarda en un tubo de Nunc de $3 \mathrm{ml}$ dentro de una nevera portátil de nitrógeno líquido para su traslado y posterior almacenamiento en un container grande. 


\section{Estudio histológico}

La lesión renal es evidenciable desde el punto de vista histológico como degeneración y/o necrosis. Las biopsias en cuña que se obtienen del riñón a lo largo del proceso experimental se guardan en un tubo Eppendorf que contiene formol al 10\% para su examen histológico al microscopio óptico.

\section{MÉTODOS ANALÍTICOS Y PROCESAMIENTO DE MUESTRAS Pruebas bioquímicas}

La determinación de la creatinina sérica y en orina se realizó mediante la reacción cinética tamponada de Jaffé sin desproteinización en un analizador Cobas Mira S (Roche).

El principio de este método se basa en que, en medio alcalino, la creatinina forma con el ácido pícrico un complejo de color amarillo rojizo. La intensidad del color es directamente proporcional a la concentración de creatinina y se determina fotométricamente a $500 \mathrm{~nm}$. La imprecisión del método para la creatinina sérica se determinó en dos sueros control comercial (Precinorm y Precipath, Roche) a dos niveles de concentración. La imprecisión intraserie fue del $1 \%$ y la interserie del $1,7 \%$ a los dos niveles.

\section{Método analítico para la determinación de nucleótidos de la adenina y sus derivados metabólicos}

La concentración de ATP y de los nucleótidos derivados de su degradación metabólica se han determinado, en el tejido renal, por cromatografia líquida de alta resolución (HPLC) ${ }^{46}$.

Se ha elegido este método por considerar que se trata de una técnica de mayor sensibilidad que los métodos enzimáticos, y sólo requiere de pequeñas muestras de tejido para su cuantificación.

\section{Procesamiento}

A las muestras de tejido renal se les añadió ácido perclórico ( $1 \mathrm{ml}, 0,6 \mathrm{~N})$ a una temperatura de $4{ }^{\circ} \mathrm{C}$ con la finalidad de homogeneizar y separar los compuestos de interés de la matriz proteica. Posteriormente, las biopsias fueron homogenizadas con un sistema Polytron 10 ST durante $3 \times 10$ segundos manteniendo el medio a $4^{\circ} \mathrm{C}$ me- diante inmersión de las muestras en baño de hielo. Tras centrifugación a $1500 \mathrm{rpm}$ durante 5 minutos manteniendo la temperatura, el sobrenadante obtenido $(0,5 \mathrm{ml})$ fue neutralizado con carbonato potásico al $9 \%$ hasta obtener un $\mathrm{pH} 7$ $(0,3 \mathrm{ml})$. Una vez transcurridos 15 minutos, se realizó una segunda centrifugación en frío para separar el precipitado del perclorato potásico formado.

El extracto neutralizado obtenido fue diluido a la mitad con tampón de dihidrogenofosfato de amonio $0,10 \mathrm{M}$ (fase móvil), e inyectado para su análisis en el sistema cromatográfico.

\section{Análisis cualitativo y cuantitativo por cromatografia en fase reversa}

La determinación de las concentraciones de los nucleótidos y sus derivados se realizó mediante HPLC en columna de fase reversa de 20 $\mathrm{cm}$ de longitud y $0,4 \mathrm{~cm}$ de diámetro interno empaquetadas con Nucleosil C.18, de 5 micrometros de diámetro de partícula.

Para la fase móvil se utilizó un tampón dihidrogenofosfato de amonio $0,10 \mathrm{M}$ preparado a partir de 6,7 $\mathrm{ml}$ de ácido fosfórico (PO4H3) al 85\% por litro y amoniaco (NH4) al 25\% hasta alcanzar un $\mathrm{pH}=6$. El flujo se mantuvo a $1 \mathrm{ml} / \mathrm{mi}$.

Una vez obtenidos los cromatogramas, se identificaron los metabolitos de las muestras en estudio, mediante la comparación de los tiempos de retención en la columna con los tiempos obtenidos de una mezcla de estándares de ATP, ADP, AMP, hipoxantina y xantina de concentración conocida.

Las concentraciones de las sustancias en estudio (expresadas en $\mathrm{mmol} / \mathrm{ml}$ de extracto), se obtuvieron por extrapolación de las áreas del cromatograma sobre rectas de calibración construidas a partir de cinco concentraciones distintas de estándares.

A partir del valor de las concentraciones de nucleótidos en las biopsias se calcula para cada muestra de tejido renal la proporción sobre el basal de cada nucleótido y derivados (ATP+ADP+ AMP+Hipoxantina+Xantina) en cada fase del estudio y la carga energética de adenilatos (CE). Para esta última, se ha empleado la siguiente fórmula de Atkinson descrita en la literatura ${ }^{47}$ :

$$
\mathrm{CE}=(\mathrm{ATP}+1 / 2 \mathrm{ADP}) /(\mathrm{ATP}+\mathrm{ADP}+\mathrm{AMP})
$$




\section{Muestras histológicas}

Procesamiento de las muestras

Se obtuvieron muestras en cada una de las etapas del estudio:

Basal (B), final de isquemia caliente o parada cardiada (PC), final de isquemia fría (PR) y $5^{\circ}$ día (5D).

El examen anatomopatológico se realizó con el microscopio óptico. El material para microscopía óptica fue fijado en una solución de formol al $10 \%$ e incluido en parafina. La inclusión se realizó con un procesador de tejido Citadel 2000 de Shandon. El punto de fusión de la parafina utilizada fue de $58^{\circ}-60^{\circ} \mathrm{C}$.

Los bloques de tejido parafinado fueron cortados con un microtomo de rotación de ReichertJung 2035 hasta obtener cortes de tejido con un espesor aproximado de 3 micras. Estos cortes fueron desparafinados y teñidos con HematoxilinaEosina.

Valoración anatomopatológica de las muestras

Para clasificar los riñones en viables y no viables se siguió el criterio anatomopatológico en la muestra histológica tomada al $5^{\circ}$ día. Se definió como Riñón no viable: aquel que presentaba necrosis cortical. Esto se comparó con la evolución clínica del animal y la existencia o no de diuresis (habíamos observado orinar al cerdo y/o presentaba orina al 5D en pelvis renal).

A continuación se exponen los criterios anatomopatológicos teóricos que se han seguido para clasificar el grado de las lesiones a nivel de las diferentes células de la nefrona y vasos, detectadas en las muestras de biopsias renales obtenidas en los diferentes tiempos evolutivos.

\section{Valoración de la necrosis}

Se realizó de modo cualitativo. La necrosis cortical fue valorada como presente o ausente y en los casos en que se observó necrosis cortical parcial se describió el porcentaje de área afectada respecto al total de la muestra estudiada. Muestra una afectación difusa de todos los componentes de la corteza renal. Los cambios típicos de necrosis consisten, básicamente, en una marcada eosinofilia celular global con preservación de los limites celulares.

La necrosis tubular aguda fue valorada en 4 grados (0: ausente, 1: leve, 2: moderada, 3: severa) en función de la extensión y severidad de las lesiones observadas en el examen histológico de las muestras. Resultó dificultosa de evaluar en los casos en que se observó algún signo de rechazo. Se manifiesta característicamente por un edema en la región intersticial acompañado de un escaso infiltrado inflamatorio que no afecta a las células tubulares. Frecuentemente, los túbulos muestran lesiones leves y focales que consisten en dilatación de la luz tubular y adelgazamiento del citoplasma de las células epiteliales tubulares. El borde luminal "en cepillo" de las células tubulares se halla alterado, estando parcial o totalmente ausente. También puede observarse ruptura de la membrana basal y fenómenos de apoptosis en múltiples puntos de la nefrona. A diferencia de la necrosis cortical, no se observa afectación de los glomérulos y vasos, aunque ocasionalmente se evidencian trombos de fibrina en los vasos intraglomerulares. En ocasiones, se pueden apreciar fenómenos de regeneración tubular con aumento del tamaño nuclear y presencia de nucleolo evidente.

\section{Valoración del rechazo}

Se realizó según los criterios de Banff correspondientes a la revisión de $1997^{48}$ :

Criterios cuantitativos para:

\section{Tubulitis ("T")}

TO No células mononucleadas en los túmulos

T1 Focos con 1 a 4 células/sección tubular o 10 células tubulares

T2 Focos con 5 a 10 células/sección tubular

T3 Focos con $>10$ células/sección tubular, o presencia de al menos 2 áreas de membrana basal destruida acompañada por inflamación i2/i3 y t2 tubulitis en otra parte de la biopsia

Inflamación Intersticial por mononucleares ("i")

IO Inflamación inexistente o trivial $(<10 \%$ del parénquima afecto)

I1 10 al 25\% de células inflamatorias en el parénquima

I2 26 al $50 \%$ del parénquima inflamado

I3 $>50 \%$ del parénquima inflamado

Indica la presencia de un número remarcable de eosinófilos, polimorfonucleares y/o células plasmáticas. 


\section{Glomerulitis temprana del injerto (" $\mathrm{g}$ ")}

G0 No glomerulitis

G1 Glomerulitis en la minoría de glomérulos

G2 Glomerulitis segmental o global (25-75\% de glomérulos)

G3 Glomerulitis global en todos o casi todos los glomérulos

\section{Arteritis intimal ("V")}

VO No arteritis

V1 Arteritis intimal media-moderada en, al menos, una sección arterial

V2 Arteritis intimal severa con pérdida, como mínimo, del 25\% del área luminal de, al menos, una sección arterial transversa

V3 Cambio fibrinoide arterial y/o arteritis transmural con necrosis del músculo liso de la media

Valoración de otras lesiones observadas

En algunas muestras se observaron evidentes lesiones de pielonefritis aguda. Ello dificultó la evaluación de las lesiones propias del daño por isquemia-reperfusión. En los casos en que la muestra se tomó en el animal muerto, se observó autolisis.

\section{Método de análisis estadístico de los resultados ${ }^{49-51}$}

En el estudio individual de las variables, éstas se expresaron en tanto por uno respecto al valor basal. De este modo, se consigue evaluar el cambio experimentado en cada fase independientemente del valor inicial y relativizar la evolución temporal.

Los valores semicuantitavos con los que se expresaron las lesiones histológicas, se transformaron a una escala numérica ordinal, donde 0 corresponde a ausencia de lesiones, 1 corresponde al grado leve, 2 al grado moderado y 3 al severo. Los resultados cuantitativos se expresaron como medias con su error estándar (EE).

La comparación de las medias en las diferentes fases del estudio, así como el efecto de la isquemia caliente, se realizó con el análisis de la variancia o mediante el método de Kruskal-Wallis.
El análisis de la variancia se llevó a cabo comprobando previamente si se cumplian las condiciones de aplicabilidad: normalidad de las variables (se realizó el test de normalidad de Anderson-Darling) y homogeneidad de la variancia (se comprobó mediante el test de Bartlett ). También se realizó un análisis de los residuos. Para la comparación de medias entre dos categorías se usó el método de Fisher.

Cuando no se pudo aplicar el análisis de la variancia, se usó un método no paramétrico, el test de Kruskal-Wallis. En este caso, para la comparación de medias entre dos categorías se usó el método Mann-Withney.

Se tomó como significación estadística $\mathrm{p}<0,05$.

\section{RESULTADOS}

\section{Análisis de la supervivencia según el tiempo de isquemia}

La supervivencia a los 5 días del trasplante, obtenida en los diferentes grupos y en función del tiempo de parada cardíaca (PC), está reflejada en la Figura 4 y en la Tabla 1.

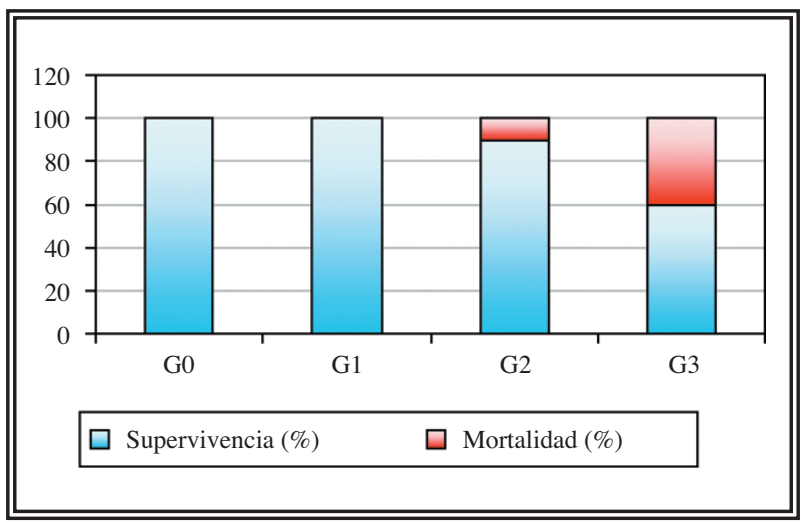

FIGURA 4. Supervivencia de los animales.

Tabla 1. Número de casos por cada grupo de isquemia en función de la supervivencia

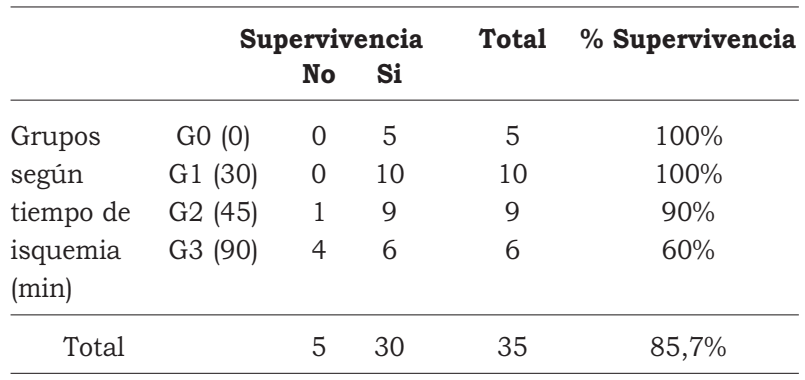




\section{Análisis de la viabilidad del órgano según el tiempo de isquemia}

La viabilidad de los órganos a los 5 días del trasplante, obtenida en los diferentes grupos y en función del tiempo de parada cardiaca (PC) queda reflejada en la Figura 5 y en la Tabla 2.

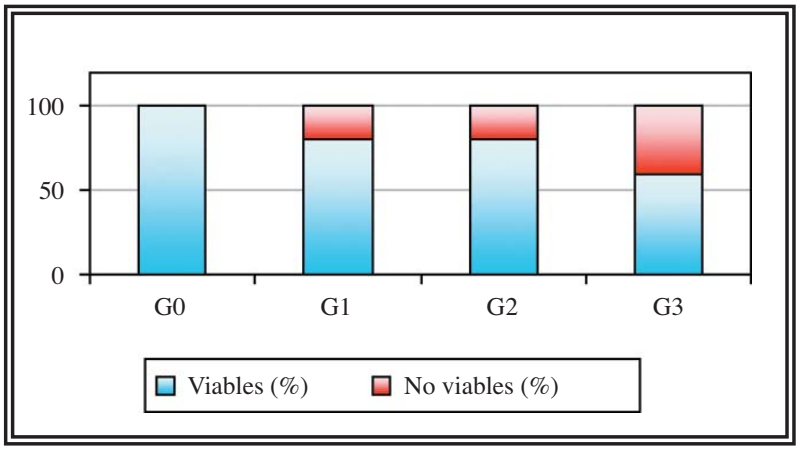

FIGURA 5. Viabilidad de los órganos.

Tabla 2. Número de casos por cada grupo de isquemia en función de la viabilidad

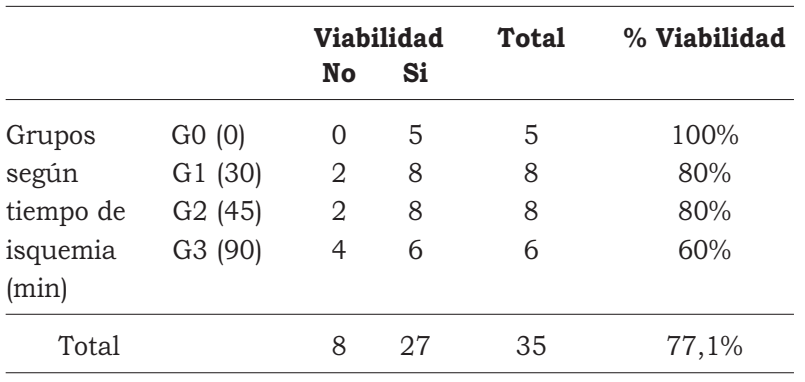

\section{Análisis de los marcadores}

El estudio de cada marcador se dividió en tres partes:

1. Efecto de la isquemia caliente sobre la variable

Se estudia fase a fase la existencia de diferencias de la variable entre los diferentes grupos del estudio: Control: 0 minutos de isquemia (G0), 30 minutos de isquemia caliente $(\mathrm{G} 1), 45$ minutos (G2) y 90 minutos (G3).

\section{Evolución temporal de la variable}

Se analiza la evolución de la variable a lo largo de las fases. Si no se apreciaron diferencias entre los grupos de isquemia caliente, se analizó la evolución temporal conjuntamente. Si hubo diferencias, se estudió cada grupo de forma individual. El grupo control se analizó siempre por separado.
3. Relación entre la variable con la viabilidad del órgano

Se estudia en cada fase la existencia de diferencias de la variable entre los órganos viables y no viables y también la evolución temporal de los mismos.

\section{ESTUDIO DE MARCADORES BIOQUÍMICOS. CREATININA}

\section{Efecto de la isquemia caliente}

El grupo control y el de $30 \mathrm{~min}$. de isquemia presentaron niveles de creatinina similares en cada fase. Sólo se diferenciaron al 1D en que en el grupo de 30 min. de isquemia fue más alta la creatinina de forma significativa. A partir de 45 min., sí hay diferencias del nivel de creatinina con el grupo control en $1 \mathrm{D}, 3 \mathrm{D}$ y $5 \mathrm{D}$. El grupo de 90 min. de isquemia presentó en las fases anteriores niveles de creatinina superiores al resto de los grupos, con significación estadística. Entre los grupos de 30 y $45 \mathrm{~min}$. no hubieron diferencias (Fig. 6).

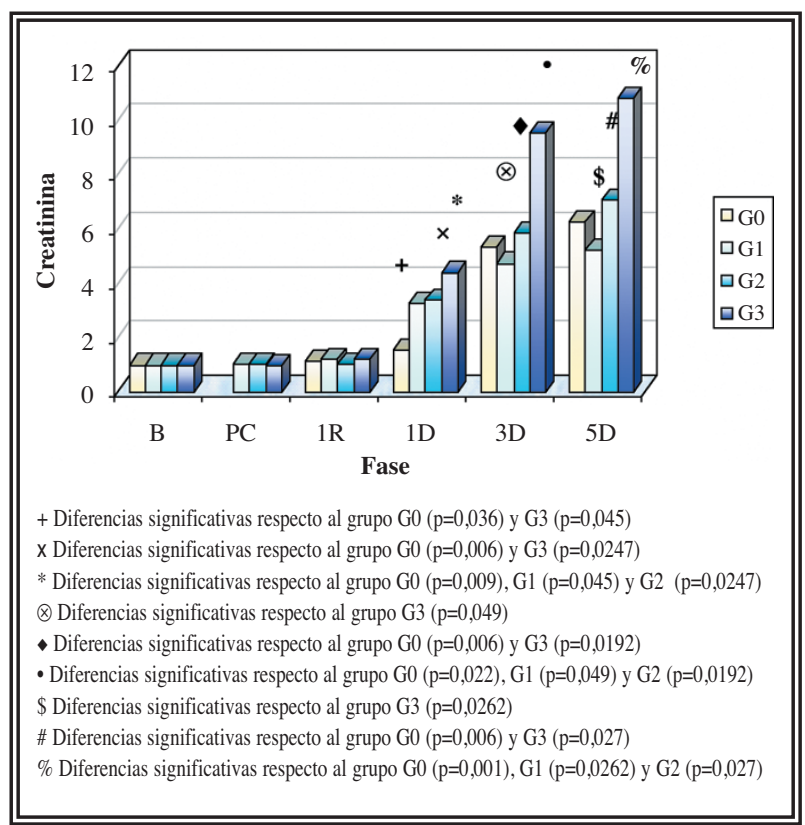

FIGURA 6. Efecto de la isquemia sobre la creatinina.

\section{Creatinina y viabilidad del órgano}

Se estudió la evolución temporal de los valores de creatinina en los riñones viables y en los no viables (Fig. 7).

Tanto en los órganos viables como no viables los niveles de creatinina aumentan progresivamente 


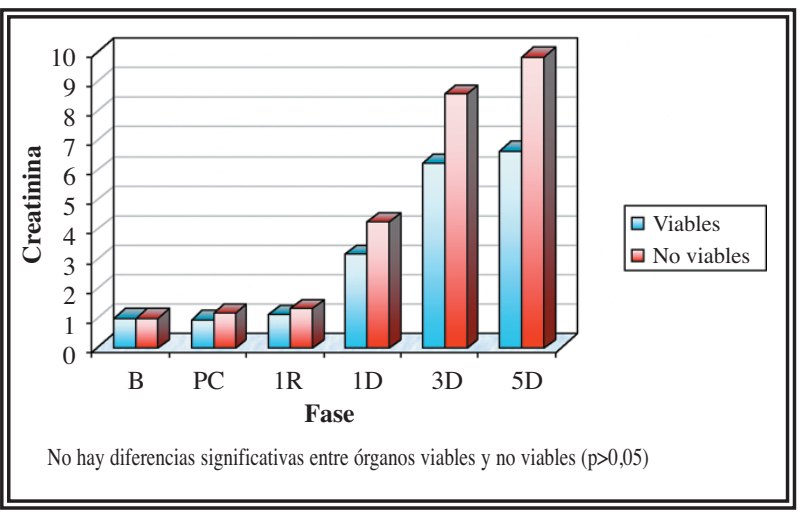

FIGURA 7. Evolución de la creatinina en los órganos viables y en los no viables.

hasta 5D. Aunque los riñones no viables presentaron niveles de creatinina superiores a los viables en las fases $1 \mathrm{D}, 3 \mathrm{D}$ y $5 \mathrm{D}$, no lo hace estadísticamente.

\section{ESTUDIO DEL ESTADO ENERGÉTICO CELULAR. ATP. ADP. AMP \\ Efecto de la isquemia caliente}

Se apreciaron diferencias significativas en los niveles de ATP en la fase PC entre el grupo G1 con el G2 $(p=0,027)$ y el G3 $(p=0,0011)$. Los niveles de ATP en los grupos de mayor isquemia son menores significativamente que en el grupo de 30 min. de isquemia (Fig. 8).

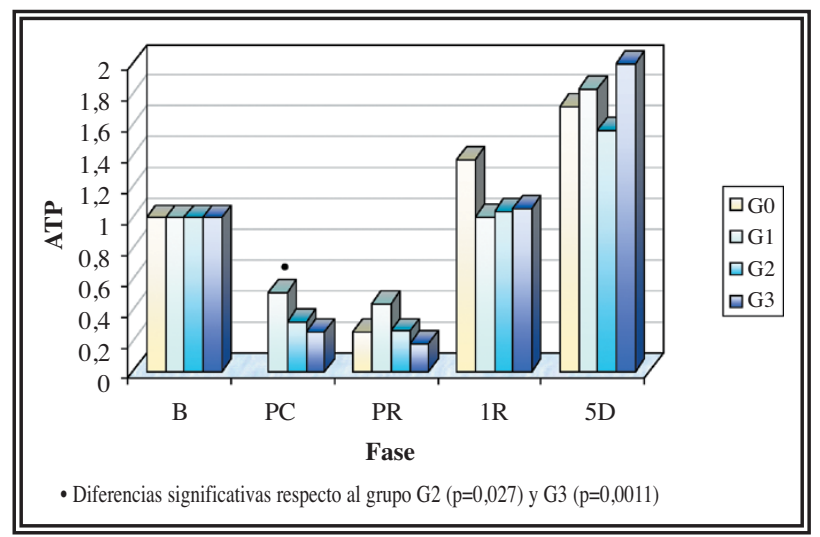

FIGURA 8. Efecto de la isquemia sobre el ATP.

\section{ATP y viabilidad del órgano}

Se estudió la evolución temporal de los valores de ATP en los riñones viables y en los no viables.

Los riñones no viables tenian niveles de ATP menores que los viables en todas las fases, pero tanto en PC como en 5D de forma significativa (Fig. 9).

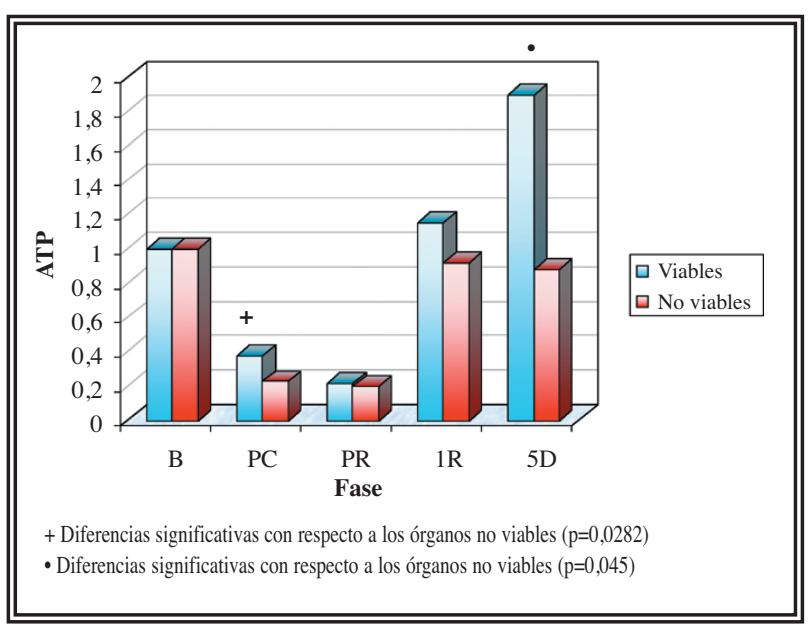

FIGURA 9. Evolución del ATP en los órganos viables y en los no viables.

En los órganos viables y en los no viables, los niveles de ATP descendieron progresivamente en PC hasta PR de forma significativa. En la fase $1 R$ los niveles se recuperan equiparándose a los basales, Sin embargo, mientras que los riñones viables presentaron en $5 \mathrm{D}$ un fuerte aumento del nivel de ATP de forma significativa, los no viables no lo consiguieron (Figs. 10 y 11).

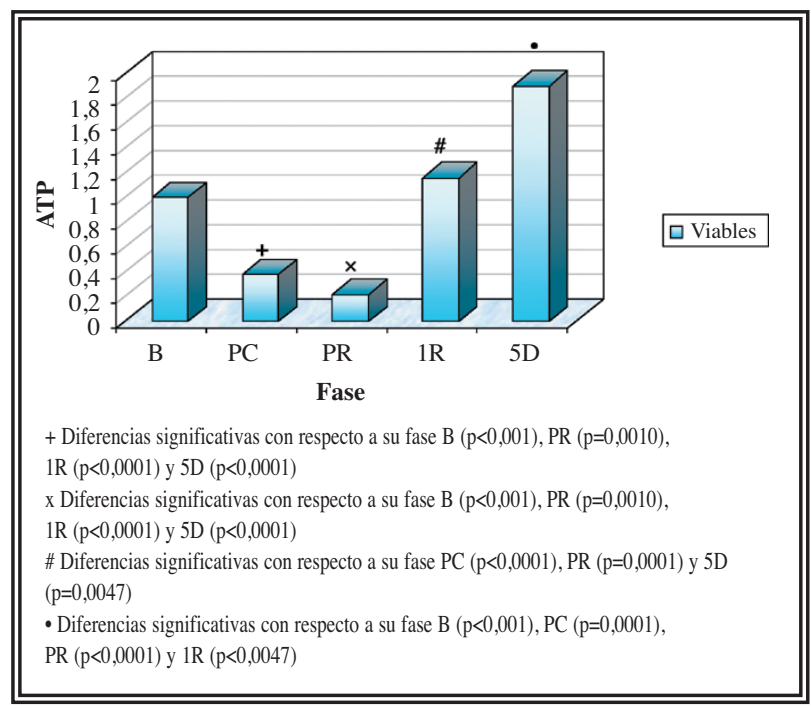

FIGURA 10. Evolución del ATP en los órganos viables.

Efecto de la isquemia caliente sobre el ADP

No se apreciaron diferencias significativas en los valores de ADP entre los grupos G0, G1, G2, G3, en ninguna de las fases del estudio (Fig. 12). 


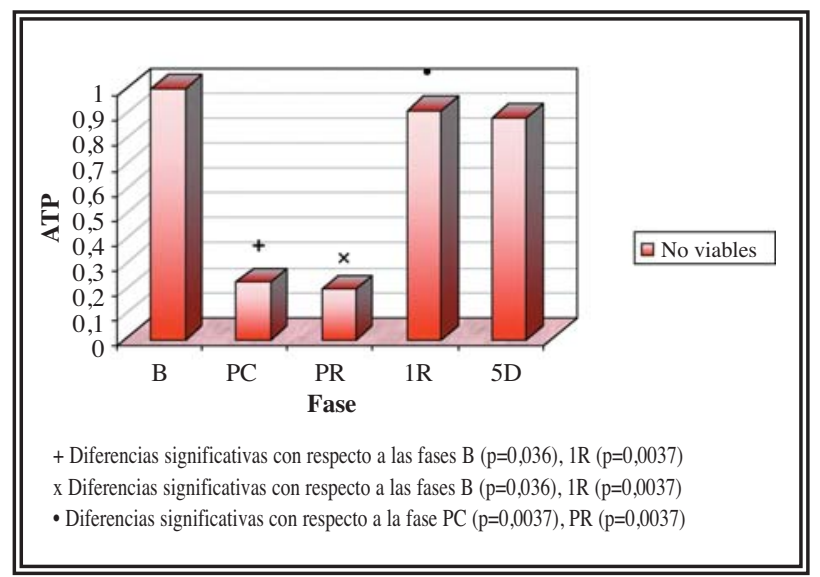

FIGURA 11. Evolución del ATP en los órganos no viables.

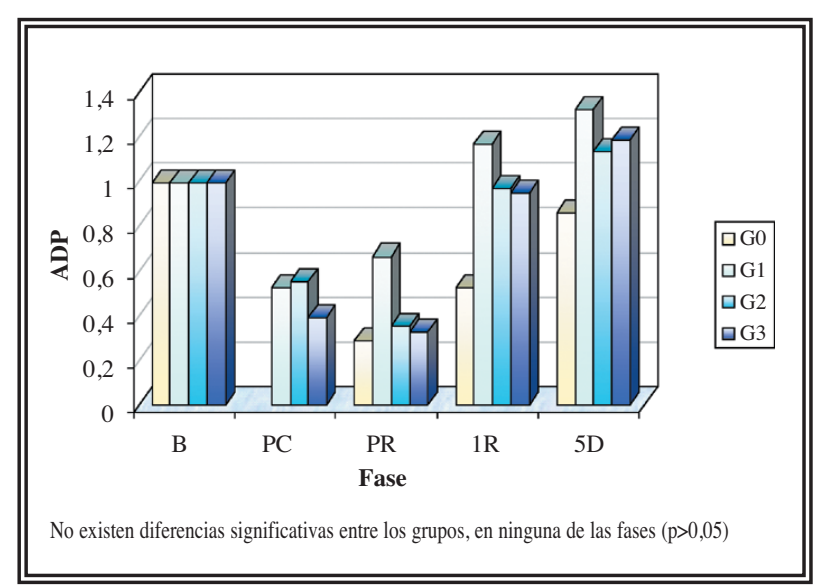

FIGURA 12. Efecto de la isquemia sobre el ADP.

\section{ADP y viabilidad del órgano}

Se estudió la evolución temporal de los valores de ADP en los riñones viables y no viables.

Los riñones no viables tenían niveles de ADP menores que los viables a lo largo de todas las fases, pero tanto en PR como en 5D de forma significativa (Fig. 13).

Efecto de la isquemia caliente sobre el AMP

Se observaron diferencias significativas en los niveles de AMP en las fases de PC entre el grupo G3 con el G1 (p=0,0051) y con el G2 ( $p=0,0073)$ y PR entre el grupo G3 con el G0 ( $p=0,0235)$, con el G1 ( $p=0,0435)$ y con el G2 ( $p=0,0140)$ (Fig. 14).

\section{AMP y viabilidad del órgano}

Se estudió la evolución temporal de los valores de AMP en los riñones viables y en los no viables (Fig. 15).

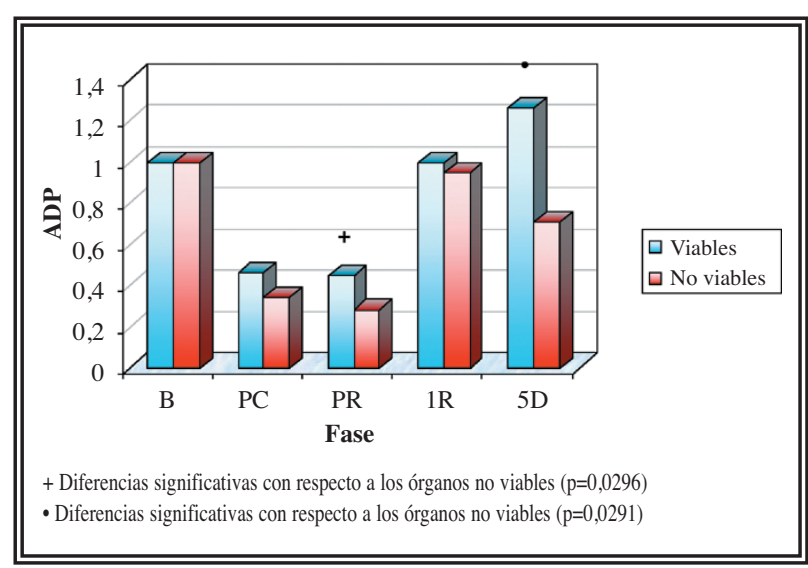

FIGURA 13. Evolución del ADP en los órganos viables y en los no viables.

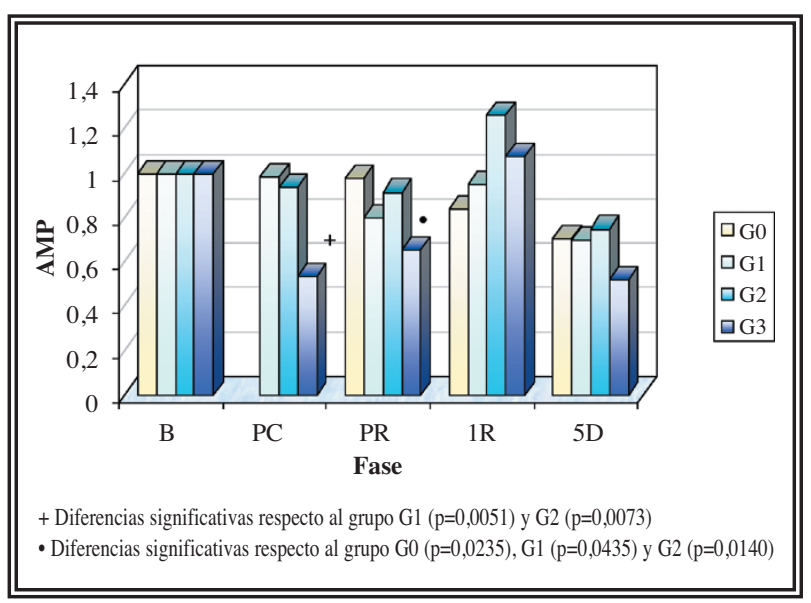

FIGURA 14. Efecto de la isquemia sobre el AMP.

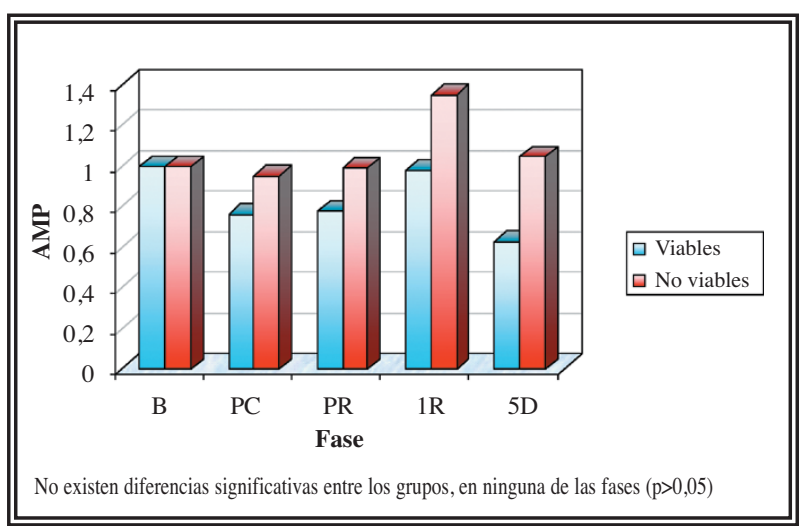

FIGURA 15. Evolución del AMP en los órganos viables y en los no viables.

En los riñones viables se produce un descenso significativo del nivel de AMP hasta la fase PR con respecto al nivel basal, alcanzando en $1 \mathrm{R}$ niveles parecidos a los basales, para caer de nuevo al $5 \mathrm{D}$ por debajo de éstos de forma significativa. 


\section{XANTINA E HIPOXANTINA}

Efecto de la isquemia caliente

No se apreciaron diferencias significativas en los valores de la xantina e hipoxantina (XHX) entre los grupos G0, G1, G2, G3, en ninguna de las fases del estudio (Fig. 16).

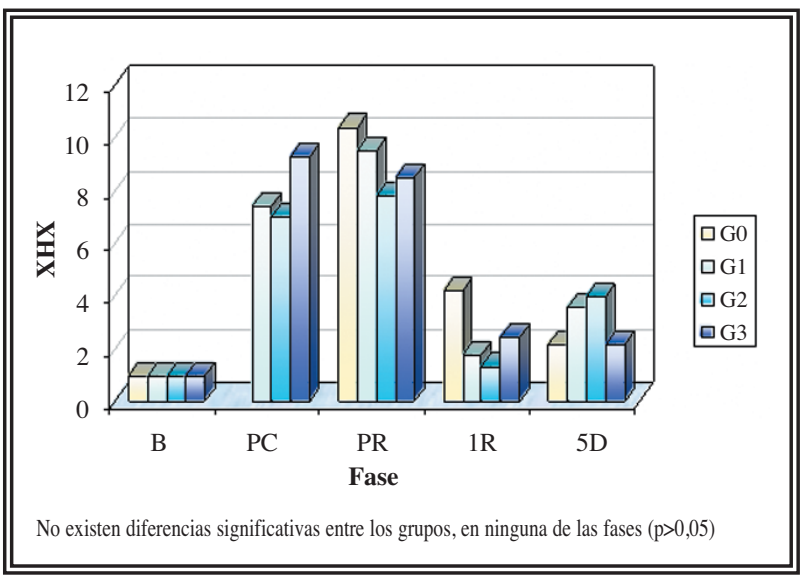

FIGURA 16. Efecto de la isquemia sobre la XHX.

\section{Evolución temporal del nivel de XHX}

Dado que no existen diferencias significativas entre los grupos G1, G2, G3 en ninguna de las fases, estudiamos la evolución temporal del grupo G0 y la de los grupos G1, G2 y G3 conjuntamente.

\section{Grupo GO}

Se produce un significativo aumento de los niveles de XHX en PR con respecto a los niveles basales, para descender progresiva y significativamente en $1 \mathrm{R}$ y $5 \mathrm{D}$ (Fig. 17).

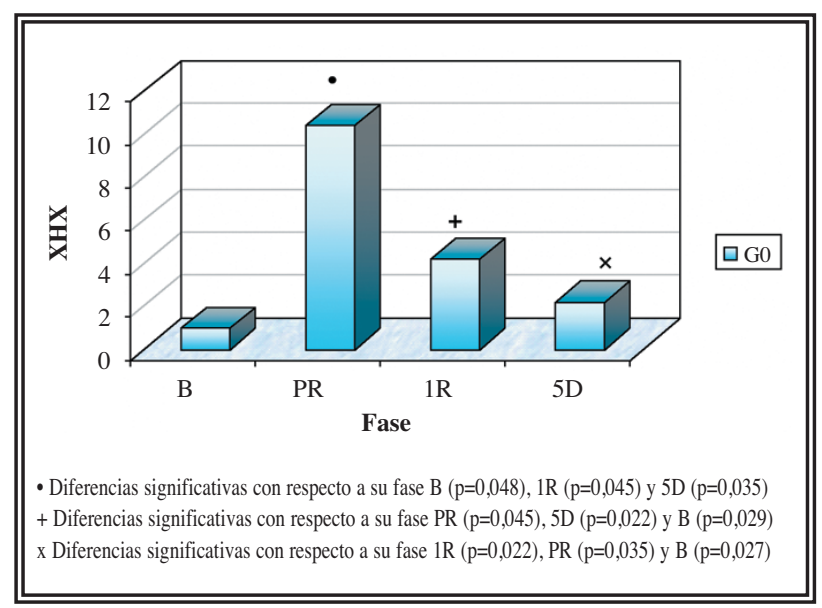

FIGURA 17. Evolución de la XHX en el grupo GO.

\section{Grupos con isquemia}

Se produce un aumento significativo de los niveles de XHX en PC y PR con respecto a los basales. Posteriormente descienden, pero quedando aún por encima de los basales de modo significativo (Fig. 18).

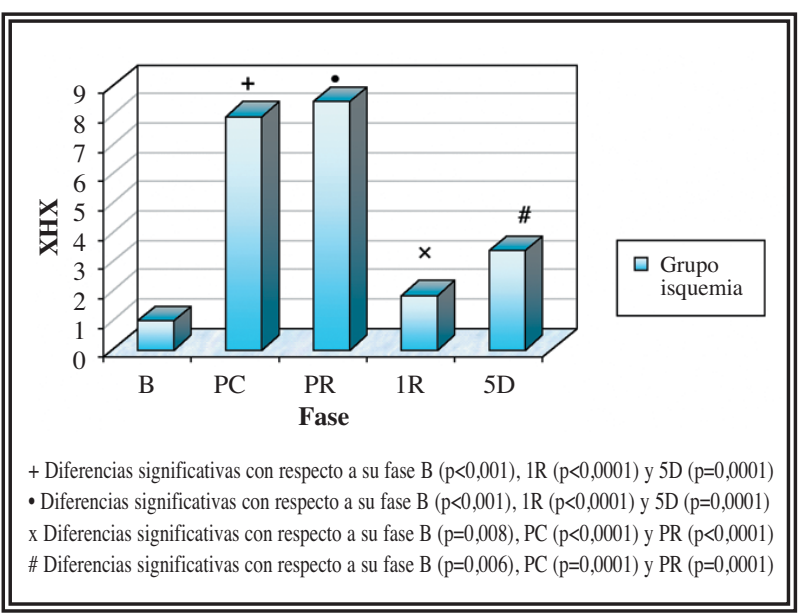

FIGURA 18. Evolución de la XHX en los grupos con isquemia.

\section{XHX y viabilidad del órgano}

Se estudió la evolución temporal de los valores de la XHX en los riñones viables y en los no viables.

Los riñones no viables tenían niveles de XHX muy superiores a los viables en $5 \mathrm{D}$, de forma significativa (Fig. 19). En los riñones viables y no viables, los niveles de XHX de aumentaron de forma significativa con respecto a los basales en las fases PC hasta PR. En la fase 1R se produce un descenso significativo. Sin embargo, al 5D los riñones viables no modificaron sus niveles, mientras que los no viables los aumentaron.

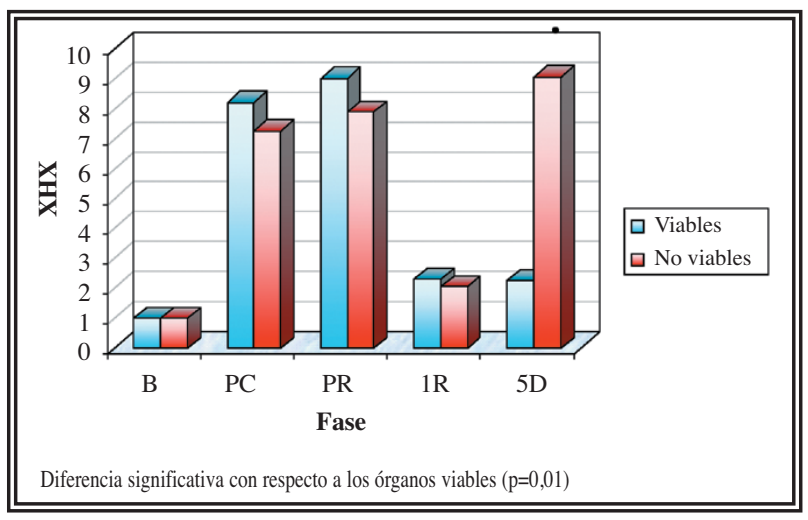

FIGURA 19. Evolución de la XHX en los órganos viables y en los no viables. 


\section{CARGA ENERGÉTICA GLOBAL \\ Efecto de la isquemia caliente}

No se apreciaron diferencias significativas en los valores de la carga energética (CE) entre los grupos G0, G1, G2, G3, en ninguna de las fases del estudio (Fig. 20).

\section{CE y viabilidad del órgano}

Se estudió la evolución temporal de los valores de la $\mathrm{CE}$ en los riñones viables y en los no viables (Fig. 21).

Tanto órganos viables como no viables presentaron pérdida de carga energética tras PC y $P R$, que recuperan de forma significativa en $1 R$. Sin embargo, los órganos viables continúan esta recuperación en $5 \mathrm{D}$ mientras que los no viables se frenaron, existiendo en esta fase una diferencia significativa entre ambos: los órganos viables presentaron mayor carga energética.

\section{ESTUDIO HISTOLÓGICO \\ Muestras intraoperatorias}

Los cambios observados en las muestras intraoperatorias (basal, final de parada cardiaca

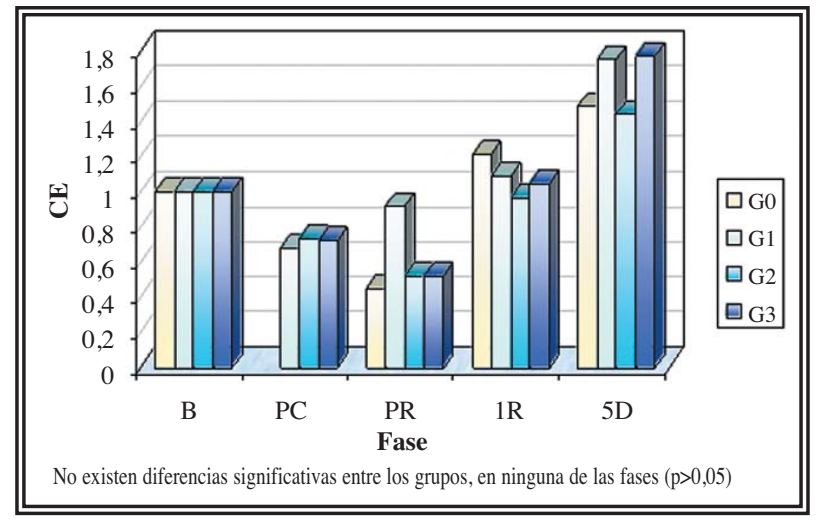

FIGURA 20. Efecto de la isquemia sobre la CE.

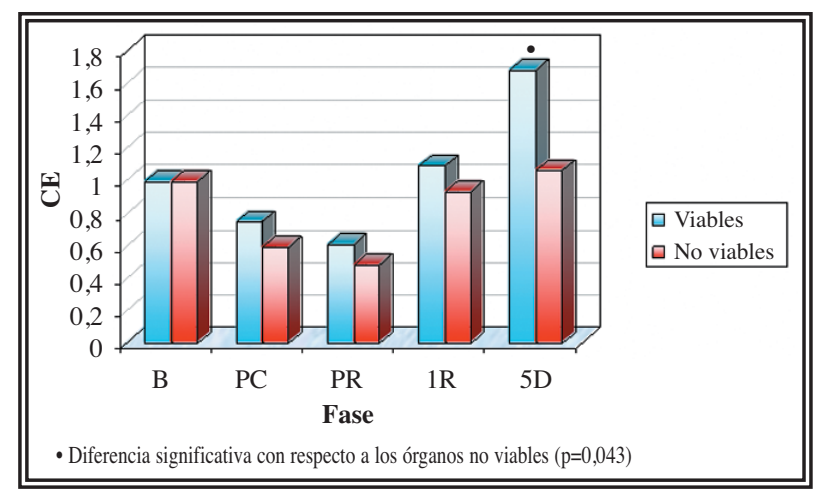

FIGURA 21. Evolución de la CE en los órganos viables y en los no viables. y final de isquemia fría) no fueron destacables. Únicamente destacó la presencia de una vacuolización citoplasmática e hinchazón celular en algunas muestras correspondientes al final de isquemia fría. Se trata de lesiones que, en principio, son reversibles. La vacuolización debida a la isquemia plantea el diagnóstico diferencial con la que, en ocasiones, se produce durante el procesamiento histológico habitual de las muestras.

\section{Muestras al quinto dia}

Grupo control

No se observaron cambios de necrosis cortical en ninguno de los animales del grupo. Únicamente, de los cinco animales del grupo, destacaron dos casos de necrosis tubular aguda leve (NTA leve) (Tabla 3). Se observaron signos leves de tubulitis en tres animales. Un animal presentó signos de rechazo vascular.

Grupo de 30 minutos de isquemia

Se observó necrosis cortical en dos animales; en uno de ellos con afectación del $10 \%$ y en el otro del $100 \%$ de la muestra. Cinco animales presentaron NTA: dos moderada y tres leve. Tres animales no presentaron necrosis (ni tubular ni cortical). Los cambios de tubulitis, glomérulos e intersticio fueron leves. Se evidenció dos casos de rechazo vascular.

\section{Grupo de 45 minutos de isquemia}

Dos animales presentaron necrosis cortical. 6 animales presentaron NTA; 5 leve, 1 severa. Dos animales no presentaron ningún tipo de necrosis. Los cambios observados a nivel de túbulos, glomérulos.

\section{Grupo de 90 minutos de isquemia}

En este grupo se evidenciaron los cambios más destacables. Cuatro casos mostraron necrosis cortical aunque tan sólo en dos fue del 100\%. En los otros dos casos fue parcial y se acompañaba de NTA muy marcada. Tan sólo un caso no evidenció cambios de NTA. La afectación intersticial y tubulitis fue moderada o grave. No se evidenció lesión glomerular ni rechazo vascular

\section{DISCUSIÓN}

El tiempo de isquemia caliente influyó en la supervivencia de los animales. El grupo control y el de $30 \mathrm{~min}$. de isquemia tuvieron $100 \%$ de supervivencia. El grupo de $45 \min$ un $90 \%$ y el 
Tabla 3. Evaluación del diagnóstico final en muestras del $5^{\circ}$ día

\begin{tabular}{lccccc}
\hline Grupo & Histologia normal & NTA leve & NTA moderada & NTA severa & Necrosis cortical \\
\hline G0 & 3 & 2 & 0 & 0 & 0 \\
G1 & 3 & 3 & 2 & 0 & $1(10 \%)$ \\
G2 & 2 & 5 & 0 & 1 & 2 \\
G3 & 1 & 2 & 3 & 0 & 4 \\
\hline
\end{tabular}

grupo de 90 min un $60 \%$. Los animales supervivientes estuvieron sometidos a un tiempo medio de isquemia de 37,5 min mientras que los que murieron tuvieron un tiempo medio de isquemia de $81 \mathrm{~min}$. Observamos, de forma estadísticamente significativa, que a mayor tiempo de isquemia mayor mortalidad.

Sorprendentemente, el tiempo de isquemia caliente de hasta $90 \mathrm{~min}$, no llega a influir, de forma decisiva.

La evolución del nivel de creatinina a lo largo de las fases del estudio es similar entre los grupos con isquemia y el grupo control. En los primeros, la elevación del nivel de creatinina, y por consiguiente, el empeoramiento de la función renal se produce de forma más precoz, ya en la fase de revascularización, mientras que en el grupo control se produce al primer día.

Aunque el tiempo de isquemia caliente influye en el nivel de creatinina (a mayor tiempo de isquemia, mayor nivel de creatinina) no acaba de ser decisivo con respecto a la viabilidad del riñón (no hubieron diferencias significativas del valor de la creatinina entre órganos viables y no viables). La función renal se altera pero no hasta el punto de que se pierda la viabilidad del riñón.

Esta elevación del nivel de creatinina es la traducción bioquímica del daño tubular renal que experimenta el órgano como consecuencia de la lesión. Numerosos trabajos clínicos ponen de manifiesto que pacientes trasplantados renales con NTA presentan niveles más elevados de $\alpha$-GST que aquellos que tienen función renal normal ${ }^{52-56}$. También la concentración urinaria del enzima $\beta$ NAG es un marcador con gran especificidad y sensibilidad diagnóstica de daño tubular en pacientes trasplantados con NTA y/o rechazo como demuestran otros trabajos clínicos.

En general, se observó una buena correlación entre los resultados obtenidos en el estudio bio- químico y el histológico. Se ha de hacer hincapié en que los resultados observados en la histología fueron sorprendentemente muy diferentes a aquellos que nosotros, a priori, esperábamos encontrar al inicio del diseño del estudio.

Se esperaba que la gran mayoría de los órganos sometidos a 90 minutos de isquemia caliente mostraran necrosis cortical al $5^{\circ}$ día, es decir, que no fueran viables. Y que en el grupo de 45 minutos hubiera un $50 \%$ de casos de necrosis cortical.

Se empezaron a detectar cambios histológicos, pero de una forma muy leve, en algunas biopsias tomadas al final de la isquemia fría. El riñón es más resistente a la isquemia que otro tipo de órganos como, por ejemplo el hígado cuya histología sí que se ve afectada de forma más precoz ${ }^{57}$. Se pudo observar, en algunas muestras, la presencia de una vacuolización citoplasmática e hinchazón celular que, en principio pueden ser atribuibles a lesión reversible por la isquemia total. No obstante, plantean el diagnóstico diferencial con fenómenos de vacuolización celular que pueden ser ocasionados por el procesamiento histológico habitual de las muestras. Podría relacionarse este hallazgo con el aumento de creatinina que ya se detecta tras la revascularización en los grupos con isquemia. En las muestras tomadas al $5^{\circ}$ día ya se ponen de manifiesto completamente las lesiones histológicas.

A medida que aumenta el tiempo de isquemia caliente, se intensifican los cambios histológicos, aumentando el porcentaje de necrosis cortical y la intensidad de necrosis tubular aguda, de tal forma que: el grupo control no presentó ningún caso de necrosis cortical, el de 30 minutos de isquemia un caso de necrosis cortical $100 \%$ y otro $10 \%$, el de 45 minutos dos casos de necrosis cortical y el de 90 minutos cuatro casos de necrosis cortical. En el grupo control y de 30 minutos 
de isquemia hubieron tres casos sin ningún tipo de necrosis, en el de 45 minutos dos casos y en el de 90 minutos un caso. El grupo de 90 minutos fue el más afectado; también fue el que presentó los niveles de creatinina más elevados.

Al igual que en otros estudios experimentales ${ }^{46,58,59-64}$ en este trabajo se comprobó que el estado energético renal es uno de los parámetros afectados como consecuencia del daño por isquemia-reperfusión en el trasplante. Se ha realizado un análisis del metabolismo de las purinas calculando los niveles de adeninnucleótidos y sus productos de degradación mediante HPLC. Maessen ${ }^{65}$ utilizó esto para intentar averiguar el tiempo de isquemia caliente de riñones donantes y decidir sobre su viabilidad clínica.

Al estudiar el estado energético, observamos que tras la fase de isquemia caliente el nivel celular de ATP y ADP decrece con respecto a la suma total de nucleótidos al comparar con los niveles basales. Esto es debido a que el ATP sufre una degradación rápida y progresiva transformándose en sus derivados metabólicos (xantina e hipoxantina) por lo que en la misma fase se detecta un aumento significativo de los mismos. La caída que experimenta el AMP tras la isquemia caliente no es significativa con respecto al nivel basal excepto cuando la isquemia caliente ya es de 90 minutos.

En relación a lo anteriormente citado, se observó también, tras parada cardíaca, una disminución significativa de la carga energética con respecto a los valores basales. La carga energética representa el balance entre energía consumida y generada.

Tras la preservación en frío, tanto en el grupo control ( $\sin$ isquemia caliente) como en el resto, continuaron cayendo los niveles de ATP y ADP como lo habian hecho tras la parada cardíaca. La carga energética también disminuyó. Y al igual que ocurría tras la parada cardíaca, los derivados metabólicos xantina e hipoxantina aumentaron en el grupo control o se mantuvieron en el grupo de isquemia reflejando la transformación de los adeninnucleótidos en ellos.

En resumen: los niveles de ATP y ADP al igual que la carga energética descienden tras la parada cardíaca e isquemia fría mientras que aumentan los derivados metabólicos de éstos.
Tras la reperfusión, se produce un incremento de los niveles de ATP, ADP e incluso AMP recuperándose la carga energética, todo ello de forma significativa (excepto en el grupo control en que el AMP disminuye). Los metabolitos xantina e hipoxantina seguirán el camino inverso. La restauración del flujo sanguíneo a los tejidos isquémicos hace que las células puedan recuperar el nivel de adeninnucleótidos si no tenían daño irreversible.

Los niveles basales de ATP y carga energética eran inferiores a los del $5^{\circ}$ dia. Tabet y otros autores también habían observado este hecho en su trabajo experimental en hígado ${ }^{66}$. Según estos autores, el ayuno previo a la intervención afectaría la reserva de glucógeno reduciendo la disponibilidad de fructosa, que es el sustrato para la formación de ATP. $\mathrm{Al} 5^{\circ}$ día postrasplante habría mejorado el estado nutricional del animal.

Todos los riñones no viables presentaron niveles menores de ATP y ADP a lo largo del estudio siendo esta diferencia significativa tras parada cardíaca (ATP) e isquemia fría (ADP) y al quinto día ambos.

Se deduce de nuestros resultados que, en cuanto a la carga energética, es la isquemia caliente en sí y no la duración de ésta lo que influye, (no se observan diferencias significativas entre los diferentes grupos de isquemia). Ahora bien, esto no se cumple en cuanto a los adeninnucleótidos ATP y AMP. En concreto, con respecto al ATP, el grupo de isquemia de 30 minutos presentó niveles de ATP mayores que el de $45 \mathrm{~min}$. y $90 \mathrm{~min}$. tras parada cardíaca. Se podría decir que a mayor tiempo de isquemia caliente se produce mayor caída del nivel de ATP con respecto al basal. En cuanto al AMP, el grupo de mayor tiempo de isquemia (90 minutos) presentó niveles más bajos tras parada cardíaca que el resto de los grupos.

En todos los grupos controles, en los que no hay isquemia caliente, tanto la carga energética, como los adeninnucleótidos (ATP y ADP) desciende tras isquemia fria de forma significativa.

Por lo tanto, tanto la isquemia caliente como la fría afecta a la caída de los adeninucleótidos.

Podríamos conseguir una verdadera aplicación clínica de estos resultados sobre el estado energético del órgano mediante el uso de la resonancia magnética espectroscópica con $\mathrm{P}^{67}$ que nos permitiría poder evaluar la viabilidad del órgano, de forma muy rápida, antes del trasplante ${ }^{68}$. 
Al analizar el estado energético mediante HPLC se ha podido demostrar la relación de éste con la viabilidad del órgano. No obstante, usando esta técnica, es imposible obtener resultados dentro del margen de tiempo clínico disponible entre la extracción y el implante.

Sin embargo, la resonancia magnética espectroscópica con $\mathrm{P}^{67}$ puede ser un medio no invasivo de evaluar la integridad del órgano donante de forma aislada antes del implante; aunque con menos especificidad que la HPLC o los análisis enzimáticos, debido a la superposición de ciertos metabolitos al usar clínicamente campos magnéticos fuertes. Durante el almacenamiento en frío, el ATP rápidamente se defosforila para convertirse en ADP y P inorgánico. El ADP se defosforilará, a su vez en AMP el cual contribuye al pico de PME (fosfomonoesteres)/Pi (fósforo inorgánico) del espectro de la resonancia magnética. La mayor ventaja de usar esta técnica es el poder medir los metabolitos energéticos casi instantáneamente durante el intervalo de tiempo entre la extracción del órgano y su posterior implante.

\section{CONCLUSIONES}

1. El tiempo de isquemia caliente influye en la supervivencia de los animales.

2. El tiempo de isquemia caliente no influye, de forma decisiva, sobre la viabilidad del órgano; sorprendentemente, afecta menos de lo esperado

3. El tiempo de isquemia caliente influye en la histología del órgano, pero no de la manera en que se podría esperar.

4. La isquemia caliente y fría afecta al estado energético celular.

5. Los niveles de adeninnucleótidos y carga energética (estado energético celular) están implicados en la viabilidad del órgano. Los riñones viables tuvieron mayor nivel de adeninnucleótidos: ATP (tras parada cardíaca y quinto dia), ADP (tras isquemia fría y quinto día) y carga energética (quinto día) que los riñones no viables, de forma significativa.

Anexo: (El presente estudio ha recibido financiación del Fondo de Investigación Sanitaria 1998, Fundació Catalana de Trasplantament, Premio Fundación de Investigación en Urología, Premio Fin de Residencia HCP y Tesis Doctoral de Pilar Luque Gálvez).

\section{REFERENCIAS}

1. Jacobbi LM, McBride VA, Etheredge EE, McDonald JC, Cooper ES, Frey D, et al. The risk, benefits and costs of expanding donor criteria. A col.laborative prospective three-years study. Transplantation. 1995;60(12):1491-1496.

2. Alexander JW, Vaughn WK, Carey MA. The use of marginal donors for organ transplantation: The older and younger donors. Transplant Proc. 1991; 23(1 Pt 2): 905-909.

3. Vroemen JP, van der Vliet JA, Kootstra G.. The emergency in situ preservation of kidneys for transplantation. Neth J Surg. 1983 May;35(2):55-60

4. Kootstra G, Wijnen R, van Hooff JP, van der Linden CJ. Twenty percent more kidneys through a non-heart beating program. Transplant Proc. 1991;23(1 Pt 2): 910-911.

5. Statements and Recommendations on Non Heart-Beating Donors. ETCO-Newsletter November, 1995;13 (2).

6. Kootstra G, Daemen JH, Oomen AP. Categories of non-heart-beating donors. Transplant Proc. 1995;27(5):2893-2894.

7. Organización Nacional de Trasplantes. Documento de Consenso Español. Donación de órganos a corazón parado. Noviembre 1995. [Rev. Nefrologia]

8. Booster MH, Wijnen RM, Ming Y, Vroemen JP, Kootstra G. In situ perfusion of kidneys from non-heart-beating donors: The Maastricht Protocol. Transplant Proc. 1993;25(1 Pt 2): 1503-1504.

9. Kozaki M, Matsuno N, Tamaki T, Tanaka M, Kono K, Ito H, et al. Procurement of kidney grafts from non-heart-beating donors. Transplant Proc. 1991;23(5):2575-2578.

10. Rigotti P, Morpurgo E, Comandella MG, Pittoni G, Baldan N, Ganz E, et al. Non- Heart Beating donors: an alternative organ source in kidney transplantation. Transplant Proc. 1991;23(5):2579-2580.

11. Ruers TJM, Vroemen JPAM, Kootstra G. Non-heartbeating donors: A successful contribution to organ procurement. Transplant Proc. $1986 ; 18 ; 408-410$.

12. Rowinski W, Walaszewski J, Lagiewska B, Pacholczyk M. Use of kidneys from marginal and non-heart-beating donors: warm ischemia per se is not the most detrimental factor. Transplant Proc. 1993;25(1 Pt 2):1511-1512.

13. Morpurgo E, Rigotti P, Ancona E. Is warm ischemia the main limiting factor in the use of non-heart-beating donors in renal transplantation. Transplant Proc. 1993;25 (1Pt 2):1509-1510.

14. Castelao AM, Griñó JM, González C, Franco E, GilVernet S, Andrés $\mathrm{E}$, et al. Update of our experience in long-term renal function of kidneys transplanted from non-heart-beating donors. Transplant Proc. 1993;25(1 Pt 2):1513-1515.

15. Alonso A, Buitron JG, Gomez M, Fernández Garcia A, Fernández Rivera C, Oliver J, et al. Short and long-term results with kidneys from non-heart-beating donors. Transplant Proc. 1997;29(12):1378-1380.

16. Snoeijs MG, Wiermans B, Christiaans MH, van Hooff JP, Timmerman BE, Schurink GW, et al. Recipient hemodynamics during non-heart-beating donor kidney transplantation are major predictors of primary nonfunction. Am J Transplant. 2007; $7(5): 1158-1166$.

17. Sanni AO, Wilson CH, Wyrley-Birch H, Vijayanand D, Navarro A, Gok MA, et al. Non-heart-beating kidney transplantation: 6-year outcomes. Transplant Proc. 2006;38 (10):3396-3397.

18. Sánchez-Fructuoso AI, Marques M, Prats D, Conesa J, Calvo N, Pérez-Contin MJ, et al. Victims of cardiac arrest occurring outside the hospital: a source of transplantation kidney. Ann Intern Med. 2006;145(3): 157-164.

19. Teraoka S, Nomoto K, Kikuchi K, Hirano T, Satomi S, Hasegawa A, et al. Outcomes of kidney from non-heart-beating deceased donors as reported to the Japan Organ Transplant Network from April 1995December 2003: a multi center report. Clin Transp. 2004; 91-102.

20. Arias LF, Blanco J, Sánchez-Fructuoso A, Ortega L, Zuluaga MA, Conesa $\mathrm{J}$, et al. The perfusion pressure in non-heart-beating donors may expand the glomeruli. Transplant Proc. 2006;38(3): 882-884.

21. Alonso A, Fernández-Rivera C, Villaverde P, Oliver J, Cillero S, Lorenzo D, et al. Renal transplantation from non-heart-beating donors: a single-center 10-year experience. Transplant Proc. 2005; 37(9):3658-3660. 
22. Nuñez JR, Del Rio F, Lopez E, Moreno MA, Soria A, Parra D. Nonheart-beating donors: an excellent choice to increase the donor pool. Transplant Proc. 2005;37(9):3651-3654.

23. Gurkan A, Kacar SH, Varilsuha C, Karaca C, Kose S, Karaoglan M, et al. Non-heart-beating donors:is it wothwile?. Ann Transplant. 2005;10(2):20-22.

24. Brook NR, Nicholson ML. Kidney transplantation from non Heartbeating donors. Surgeon. 2003;1(6):311-322.

25. Arias-Diaz J, Alvarez J, del Barrio MR, Balibrea JL. Non Heart-beating donation:current state of the art. Transplant Proc. 2004;36 (7):1891-1893.

26. del Río Gallegos F, Nunez Pena JR, Soria García A, Moreno Roy MA, Varela A, Calatayud J. Non heart beating donors. Succesfully expanding the donor's pool. Ann Tansplant. 2004;9(2):19-20.

27. Koffman CG, Bewick M, Chang RW, Compton F. Comparative study of systolic and asystolic kidney donors between 1988 and 1991. Transplant Proc. 1993;25(1 Pt 2):1527-1529.

28. Valdes F, Pita S, Alonso A, Rivera CF, Cao M, Fontan MP, et al. Comparative study of the use of sistolic and asystolic kidney donors between 1981-1995 in La Coruña, Spain. Transplant Proc. 1997;29(8):3565-3566.

29. Hattori R, Kinukawa T, Ohshima S, Matsuura O, Ono Y, Fujita T. Outcome of kidney transplantation from non-heart-beating donors: Comparison with heart-beating donors. Transplant Proc. 1992;24(4):1455-1456

30. Weight SC, Bell PR, Nicholson ML. Renal ischaemia-reperfusion injury. Br J Sur. 1996;83(2):162-170.

31. Belzer FO, Southard JH. Principles of solid-organ preservation by cold storage. Transplantation. 1988;45(4):673-676.

32. Belzer F. Principles of organ preservation. Transplant Proc. 1988;20:925-927.

33. Mela L. Mitochondrial function in shock, ischemia and hypoxia. In: Couley RA TB ed. Pathophysiology of shock, anoxia and ischemia. Baltimore: Williams \& Wilkins Company, 1982: 84-94.

34. Granger DN, Rutili G, McCord JM. Superoxide radicals in feline intestinal ischemia. Gastroenterology. 1981;81(1): 22-29.

35. Parks D, Granger D. Ischemia- induced vascular changes: role of xanthine oxidase and hydroxyl radicals. Am J Physiol. 1983;245 (2):285-288.

36. Mc Cord JM. Oxygen derived free radicals in postischemic tissue injury. N Engl J Med. 1985;312(3):159-163.

37. Ernster L. Biochemistry of reoxygenation injury. Critical Care Medicine. 1988;16(10):947-953.

38. Hayaishi O, Shimuzu T. Metabolic and functional significance of prostaglandins in lipid peroxide research. Lipid peroxides in biology and medicine. Pag 41-43. Yagi K ed. Academia Presss, London, 1982

39. Green CJ, Healing G, Lunec J, Fuller BJ, Simpkin S. Evidence of free-radical-induced damage in rabbit kidneys after simple hypothermic preservation and autotrasplantation. Transplantation 1986;41(2):161-165.

40. Lefer AM, Lefer DJ. Pharmacology of the endothelium in isquemiareperfusion and circulatory shock. Ann Rev. Pharmacol Toxicol 1993; 33: 71-90.

41. Menger MD. Microcirculatory disturbances secondary to ischemiareperfusion. Transplant Proc. 1995;27(5):2863-2865.

42. Kubes P, Granger DN. Role of leukocytes in reperfusion-induced intestinal dysfunction. DN \& P. Mayo 1992;5(4): 197-206.

43. Fuggle SV, Koo D.H. Cell adhesion molecules in clinical renal transplantation. Transplantation. 1998;65(6):763-769.

44. Connolly JK, Guy SP, Parrot NR. Cytokine gene expression and eicosanoid production in renal reperfusion injury. Transplant Proc. 1995;27(5):2816-2818.

45. Beekhuizen H. And Van de Covel J.S. "Endothelial cell adhesion molecules in inflammation and postischemic reperfusion injury". Transplant Proc 1998; 30: 4251-4256.

46. Maessen J.G, Van der Vusse G.J, Vork M, and Kootstra G. Nucleotides, nucleosides, and oxypurines in human kidneys measured by use of reversed-phase high-performance liquid chromatography. Clin Chem 1988;34:1087-1090.

47. Atkinson D.E. The energy charge of the adenylate pool as a regulatory parameter: interaction with feedback modifiers. Biochemistry 1968; 7: 4030 .
48. Solez K, et al. Report of the third Banff conference on allograft pathology (July 20-24, 1995) on classification and lesion scoring in renal allograft pathology. Transplant Proc 1996; 28: 441-441.

49. Peña D. Estadística. Modelos y Métodos. Vol II. Modelos lineales y series temporales. 1993. Alianza Universidad Textos

50. Cuadras C.M. "Métodos de Análisis multivariante". 1981. Editorial EUNIBAR.

51. Kleinbaum DG. Applied regression analysis and other multivariable methods 1988. Second edition. PWS-Kent publishing company.

52. Bäckman L, Appelkvist EL, Ringden O, et al. Appearance of basic glutathione transferase in the urine during tubular complications in renal transplant recipients. Transplant Proc 1988;20:427-430.

53. Bäckman L, Appelkvist E.L, Ringdén O. and Dallner G. Urinary levels of basic glutathione transferase as an indicator of proximal tubular damage in renal transplants recipients. Transplant Proc 1989; 21: 1514-1516.

54. Bäckman L, Appelkvist ELL, Ringden O. and Dallner G. Glutathione transferase in the urine: a marker for post-transplant tubular lesions. Kidney Int. 1988; 33: 571-577.

55. Sundberg A.G, Appelkvist E.L, Bäckman L, et al. "Urinary pi-class glutathione transferase as an indicator of tubular damage in the human kidney". Nephron 1994;67:308-316.

56. Kotanko P, Keiler R, Knabl L, et al. "Urinary enzyme analysis in renal allograft transplantation”. Clin Chim Act. 1986;160:137-144.

57. Tabet J. Trasplante hepático experimental en el cerdo con hígado de donante a corazón parado. Tesis doctoral. Universidad de Barcelona, 1998.

58. Maessen JG, Van der Vusse GJ, Vor M, and Kootstra G. New aprroach to preservation of non-heart-beating donors: Total body cooling. Transplant Proc 1987; 19: 4159-4161.

59. Hoshino T, Maley WR, Stump K.C, et al. Evaluation of core cooling tecnique for liver and kidney procurement. Transplant Proc 1987; 19: 4123-4128.

60. Maessen JG, van der Vusse GJ, Vork M, Kootstra G. The beneficial effect of intermediate normothermic perfusión during cold storage of ischemically injured kidneys. Transplantation. 1989;47(3):409-414.

61. Mayfield KB, Ametani M, Southard JH, Belzer FO. Mechanim of action of ex vivo blood reserve in six-day preserved kidneys. Transplant Proc. 1987;19(1 Pt 2):1367-1368.

62. González FX, García-Valdecasas JC, López-Boado MA, Tabet J, Net M, Grande L et al. Adenin nucleotide liver tissue concentrations from non-heart-beating donor pigs and organ viability after liver transplantation. Transplant Proc. 1997;29(8):3480-3481.

63. Garcia-Valdecasas JC, Tabet J, Valero R, Taurá P, Rull R, García $\mathrm{F}$, et al. Liver conditioning after cardiac arrest: the use of normothermic recirculation in an experimental animal model. Transplant Int. 1998;11(6):424-432.

64. Luque P, Alvarez-Vijande R, Alcaraz A, Aguilar A, Alcoberro J, Rodriguez A, et al. Experimental study of the cellular energy charge in pig kidney transplants with non-heart-beating donors. Transplant Proc. 1999;31(6):2352-2353.

65. Maessen JG, van der Vusse GJ, Vork M, Coumans WA, Kootstra G. Assessment of warm ischemia time in donor kidneys by analysis of purine metabolism. Transplant Proc. 1987;19(1 PT 2): 1365-1366.

66. Matsuno N, Sakurai E, Tamaki I, Furuhashi K, Saito A, Zhang S, et al. Effectiveness of machine perfusion preservation as a viability determination method for kidneys procured from non-heart-beating donors. Transplant Proc. 1994; 26(4): 2421-2422.

67. Guillard G, Rat P, Haas O, Letourneau B, Isnardon JP, Favre JP. Renal harvesting after in situ cooling by intra-aortic double-balloon catheter. Transplant Proc. 1993, 25(1 Pt 2): 1505-1506.

68. Barnard ML, Changani KK, Taylor-Robinson SD. The role of magnetic resonance spectroscopy in the assessment of kidney viability. Scand J Urol Nephrol. 1997;31(5):487-492.

Correspondencia autor: Dr. R. Álvarez-Vijande García Servicio de Urología. Hospital Clínic Barcelona Villarroel, 170 - 08036 Barcelona. Tel.: 932275545 E-mail autor: ralvarez@clínic.ub.es Información artículo: Original 